\title{
Um software de autoria para a educação de surdos: integração da língua de sinais e da língua escrita
}

\author{
Carla Beatris Valentini - Universidade de Caxias do Sul - cbvalent@ucs.br \\ Cláudia Alquati Bisol - Universidade de Caxias do Sul - claudiabisol@terra.com.br \\ Marcos Eduardo Casa - Universidade de Caxias do Sul - mecasa@ucs.br \\ Esequiel Sgorla - esequiel@focco.com.br
}

\section{RESUMO}

Os ambientes informatizados oportunizam novas formas de interação nos contextos educacionais. Em se tratando de pessoas portadoras de necessidades educativas especiais, as tecnologias digitais podem potencializar a capacidade de comunicação e aprendizado. Este artigo apresenta o software de autoria Junctus, desenvolvido com o objetivo de favorecer a ligação entre língua de sinais e língua escrita, permitindo que duas formas distintas de representação, vídeo e texto, possam ser utilizadas simultaneamente por usuários surdos. O Junctus foi desenvolvido utilizando-se a plataforma orientada a objeto Java, que possui a biblioteca Java Media Framework (JMF) disponível para tratamento de vídeos digitais. Dois ambientes, Link-it e Transana, foram estudados para o desenvolvimento desse software. Apresentamos as funcionalidades do ambiente e um cenário de interação no qual um usuário surdo produz uma narrativa em língua de sinais, cria um texto escrito desta mesma narrativa e utiliza o software para fazer a ligação entre texto e imagem, aprimorando sua habilidade para a escrita. Ao integrar estes dois códigos linguiísticos através do software, o usuário pode estabelecer novas relações, compreender as diferenças e criar estratégias próprias de uso dessas duas línguas. Discute-se ainda aplicações possíveis do software em projetos de pesquisa e em contextos educativos.

Palavras Chaves: ambiente informatizado de aprendizagem, formas de representação, interação, software de autoria, surdez.

\section{An autorship software for the education of the deaf: Integration of sign language and written language}

\begin{abstract}
Computational environments offer new ways of interaction in the educational area. Considering people with special educational needs, digital technology can increase their capacity for communication and learning. This article presents the authorship software Junctus, developed to facilitate the link between sign language and written language, allowing two different forms of representation, video and text, to be used simultaneously by deaf users. The software Junctus was developed through the use of the object oriented platform Java, which has the library Java Media Framework (JMF) available to deal with digital videos. Two environments, Link-it and Transana, were studied to develop this software. We present the functionalities of the environment and an interaction scenario in which a deaf user produces a narrative in sign language, creates a written text of the same narrative and uses the software to link text and image, improving her writing skills. By connecting these two linguistic codes using the
\end{abstract}


software, the user can establish new relations, understand the differences and create his own strategies to use these two languages. We also discuss possible applications for the software in research projects and in educational contexts.

Key Words: learning computational environments, forms of representation, interaction, autorship software, deafness.

\section{INTRODUÇÃO}

A informática está cada vez mais integrada ao processo de ensino-aprendizagem. Os recursos tecnológicos, utilizados adequadamente no cenário educativo, ampliam as alternativas que educador e educando têm para dar conta da complexidade do aprender, tornando-o um processo ao mesmo tempo lúdico e cada vez mais interativo. Na situação dos grupos especiais, ou seja, pessoas portadoras de necessidades educativas especiais (PPNEEs), o potencial dos recursos tecnológicos para renovar práticas educativas e vencer limitações é imenso. Com a introdução das tecnologias na vida das PPNEEs barreiras ligadas à autonomia, acesso ao mundo, independência e novas possibilidades de interação têm mudado significativamente as possibilidades de vida e trabalho dessas pessoas. No entanto, mais do que acessibilidade as tecnologias digitais podem atuar na direção de potencializar a capacidade de comunicação e aprendizado das PPNEEs.

Neste artigo apresentamos um ambiente desenvolvido ${ }^{1}$ como parte de um projeto de pesquisa que tem por objetivo estudar o processo de construção de narrativas de adolescentes surdos. Chamamos de Junctus a este ambiente que permite a ligação de duas formas de representação, vídeo e texto, portanto permite a ligação entre língua de sinais e língua escrita. Para as crianças surdas que nascem em famílias ouvintes (cerca de 94\%, segundo Marchesi, 1993), o desenvolvimento da linguagem pode ser muito difícil caso a família e a escola não encontrem formas satisfatórias de estabelecer uma comunicação significativa com a criança. Esta comunicação pode se dar com ênfase à utilização da língua de sinais, como preconizam a maioria dos estudos atuais e as escolas bilíngües de educação dos surdos. O aprendizado da língua escrita é difícil para o surdo, porém importante pois possibilita o acesso à leitura e à inserção social mais ampla. $\mathrm{O}$ ambiente Junctus pode ser um recurso a facilitar a ligação entre a língua de sinais, de uso natural para o surdo, e a língua escrita, oferecendo possibilidades para que o educando compare os dois sistemas lingüísticos, perceba as diferenças e construa estratégias que facilitem sua compreensão e produção da escrita.

Favorecer a interação e a exploração de diferentes formas de representação por parte do educando foi o principal objetivo norteador desse projeto. Conforme a concepção interacionista, "o conhecimento ocorre em um processo de interação entre sujeito e objeto de conhecimento, entre um indivíduo e seu meio físico e social" (Barbosa, 2005). Dentro desta concepção, os recursos de informática devem proporcionar situações de aprendizagem que facilitem ao aluno a construção da autonomia.

\footnotetext{
${ }^{1}$ O software livre Junctus foi desenvolvido como trabalho de conclusão do curso de Ciência da Computação pelo acadêmico Esequiel Sgorla, na Universidade de Caxias do Sul. Está vinculado ao projeto de pesquisa "Narrativas de Adolescentes Surdos: ambiente multimídia e construção de sentidos", do qual participam os demais autores.
} 
Em relação às diferentes formas de representação, Piaget (1978) chama de função semiótica aquela que possibilita ao sujeito representar objetos ou situações que estão fora de seu campo visual por meio de imagens mentais, de desenhos, da linguagem, da escrita, etc. Para o autor, a função semiótica é um mecanismo comum aos diferentes sistemas de representação. A função semiótica possibilita ao sujeito representar um objeto ausente por meio de um símbolo ou de um signo. A representação nasce da diferenciação e da coordenação combinadas entre significantes e significados. Ao trabalhar a língua de sinais e a língua escrita, os sujeitos que interagem no Junctus precisam tanto interpretar como produzir os elementos e suas relações, a partir da interação com o software. A possibilidade de estabelecer as ligações entre as duas formas de representação, incrementa e orienta o pensamento do aprendiz na direção das relações entre as diferentes representações, podendo vir a ser suporte de tomada de consciência dos diferentes tipos de representação com suas semelhanças e diferenças.

Como ponto de partida para este ambiente, realizamos o estudo de dois softwares já existentes - Link-it e Transana - os quais englobam características interacionistas como cooperação, interação e autonomia do aprendiz. Estes dois softwares serão rapidamente descritos a seguir.

\section{AMBIENTES DE ESTUDO}

O primeiro software analisado foi o Link-it, desenvolvido pela "Swedish Institute for Special Needs Education". Trata-se de um software proprietário, tendo como foco o público alvo usuário de língua de sinais. O Link-it possibilita a interação com o usuário, permitindo associar vídeos digitalizados com textos próprios ou obtidos através de outros recursos. Esse ambiente pode ser utilizado de diferentes maneiras, adequando-se a diferentes grupos de usuários. Dentre as diversas possibilidades, destacam-se as de criar dicionários, pequenas histórias linkadas, visualizar uma frase de cada vez em legendas, traduzir uma seção inteira em língua de sinais e criar atalhos para determinados trechos de vídeo.

O segundo software analisado é o Transana, um software livre desenvolvido por Chris Fassnacht e Davis Woods do Centro de Pesquisa e Ensino de Wisconsin, da Universidade de Wisconsin (Transana, 2005). Também possibilita a interação com o usuário através da associação entre vídeos e texto, com o adicional de áudio. É basicamente uma ferramenta para transcrição e análise qualitativa de dados. Não há uma especificidade de público alvo, podendo ser aplicado em contextos de pesquisas e de ensino.

Os critérios de análise foram agrupados em duas categorias: Interface e Pedagógicos, para após ser realizada a avaliação e comparação dos ambientes. Destacam-se as seguintes características que foram analisadas a) layout da tela: pode ser modificado pelo usuário pela definição de tamanho e localização das janelas; b) navegabilidade: facilidade de acesso a todas as partes do ambiente; c) receptividade pelo usuário: facilidade de interação; d) acesso a help: acessível, com explicações básicas das principais ferramentas e suas funcionalidades; e) carga cognitiva: utilização adequada de recursos de texto e vídeo e som; f) carga da tela: equilíbrio no uso dos elementos nas telas, evitando sobrecarga; g) facilidade de uso: clareza das funções codificadas e da apresentação das estruturas; e h) adequação dos recursos de imagem, som e animação às atividades pedagógicas. 


\section{Junctus}

Ao ambiente Junctus deu-se um nome originado do latim que significa ligado, junto, unido. Ele foi desenvolvido sobre a plataforma Java, criada pela Sun Microsystems (Java, 2005b), sendo disponibilizado como um sistema de código aberto. Esse software procurou manter as características de maior destaque no Link-it e Transana. Um dos fundamentos definidos para o desenvolvimento deste ambiente foi a necessidade de garantir uma "usabilidade" adequada, de forma que procurou-se produzir uma interface de utilização simples e que oferecesse as funcionalidades propostas para um ambiente capaz de integrar formas diferentes de representação.

Algumas das características mais importantes da plataforma Java são a sua portabilidade e o fato de incorporar uma linguagem livre com uma API (do inglês, Interface para Programação de Aplicações) extensa para as mais diversas áreas de aplicações. Ao desenvolver esse software, procurou-se encapsular as principais funcionalidades em módulos (classes) o mais independentes possível Dessa maneira cada módulo é responsável por uma determinada forma de representação, no caso do protótipo atual: vídeo e texto. Como o restante do ambiente é independente da implementação desses módulos será possível estender o sistema para incorporar outras formas de representação.

Como o Junctus precisa oferecer clips de vídeos como uma das formas de representação, desenvolvemos as funcionalidades de vídeo empregando a biblioteca JMF. A biblioteca Java Media Framework é voltada para o desenvolvimento de aplicações de mídia. O JMF adapta-se facilmente à construção de ambientes informatizados que utilizem componentes heterogêneos, tendo suporte às principais arquiteturas e codecs de áudio e vídeo.

Os vídeos são capturados a partir de filmagens digitais em geral. O software possibilita a integração entre vídeo e texto, permitindo que se estabeleça, no caso de se trabalhar com surdos, a simultaneidade entre a narrativa em língua de sinais no vídeo e a língua escrita. Para isso o usuário demarca os trechos do vídeo que corresponderão ao trecho em destaque do texto escrito, fazendo uma 'edição' de seu projeto. Cada projeto desenvolvido por um usuário-aprendiz corresponde à construção desta relação entre o texto e o vídeo. Assim é possível construir simultaneamente representações numa língua viso-espacial (língua de sinais) e numa língua escrita.

\section{Funcionalidades do Ambiente}

O Junctus apresenta diversas funcionalidades que podem ser adaptadas às necessidades do usuário. A Barra de Menu possui as seguintes opções:

a) Arquivo: operações comuns de manipulação de arquivos (Novo, Abrir, Salvar) e opção de Sair do ambiente.

b) Edição: opção de Criação, na qual disponibiliza uma janela específica para realizar as ligações entre texto e vídeo (Criação);

c) Ajuda: informações sobre o ambiente (Ajuda, Sobre), conforme apresentado na Figura 1: 




Figura 1: Ajuda do Junctus

Modo de Criação

A Figura 2 apresenta a interface do ambiente quando se inicia um novo projeto. Esta interface apresenta as seguintes janelas internas: Criação, Vídeo, Texto e Lista de Ligações. A seguir descrevemos brevemente as funções dessas janelas. 


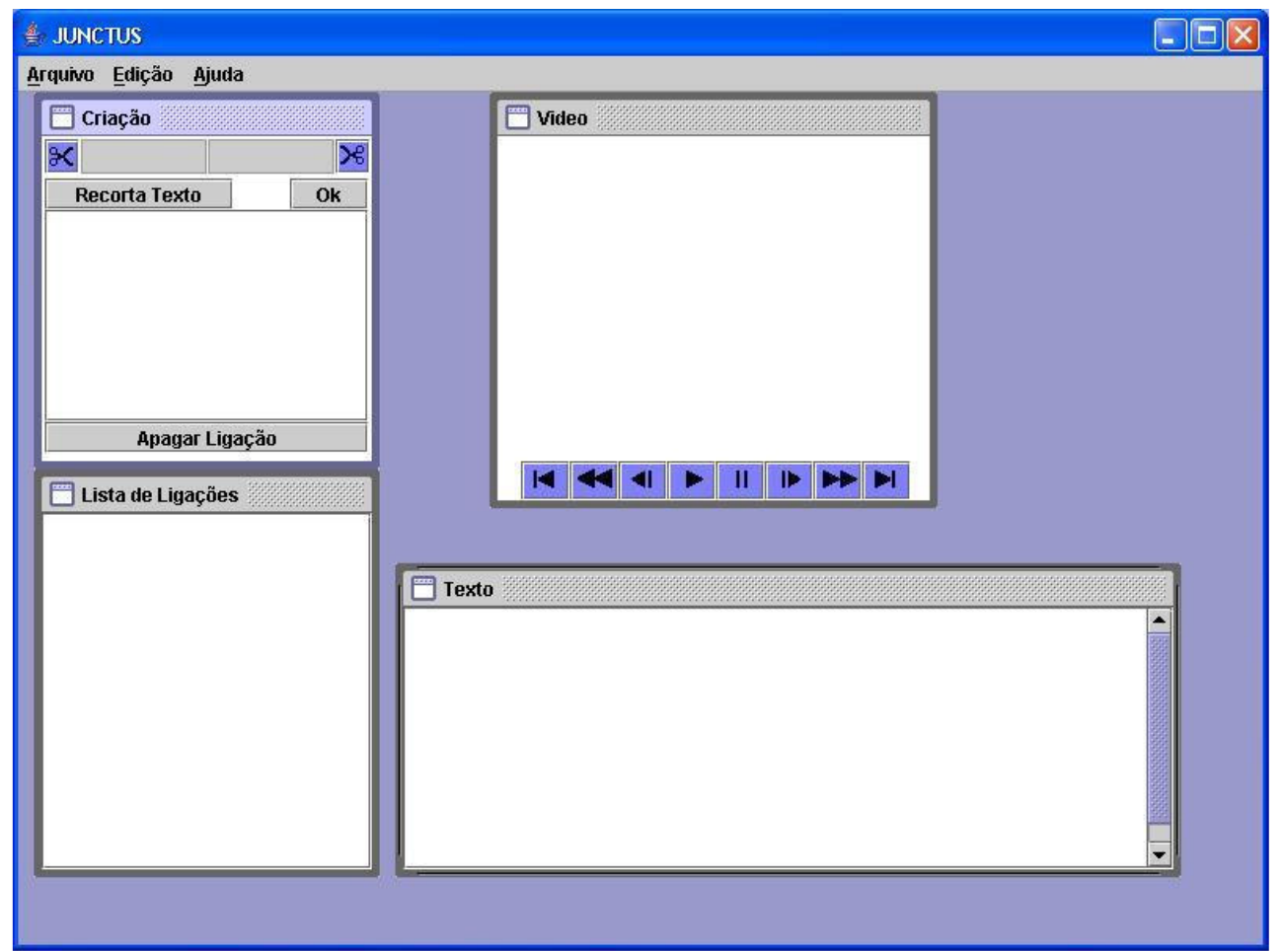

Figura 2: Tela de um novo projeto

A janela de texto pode ser usada para edição de um novo documento e/ou para adição de um documento já existente. A manipulação do vídeo é realizada com as ferramentas em destaque na Figura 3:

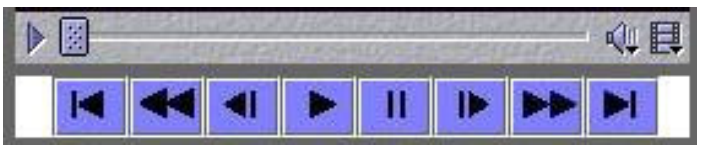

Figura 3: Ferramentas de manipulação do vídeo

Após posicionar o vídeo corretamente utiliza-se as ferramentas de recorte em destaque na Figura 4 para capturar o tempo inicial e o tempo final de um trecho do vídeo que será ligado a uma parte do texto.

\section{0:00:00 00:07:29}

Figura 4: Capturar tempos do vídeo

Com o trecho do texto e o intervalo do vídeo definidos, basta clicar no botão "OK" para confirmar a criação de uma nova ligação entre as duas formas de representação.

\section{Ferramentas de Visualização}

Para visualizar o texto associado a uma das ligações clica-se em um dos itens apresentados na janela "lista de ligações". Um clique duplo sobre um trecho de texto na "lista de ligações" fará com que o trecho do vídeo correspondente inicie e o trecho do texto fique em destaque, como mostra a Figura 5: 


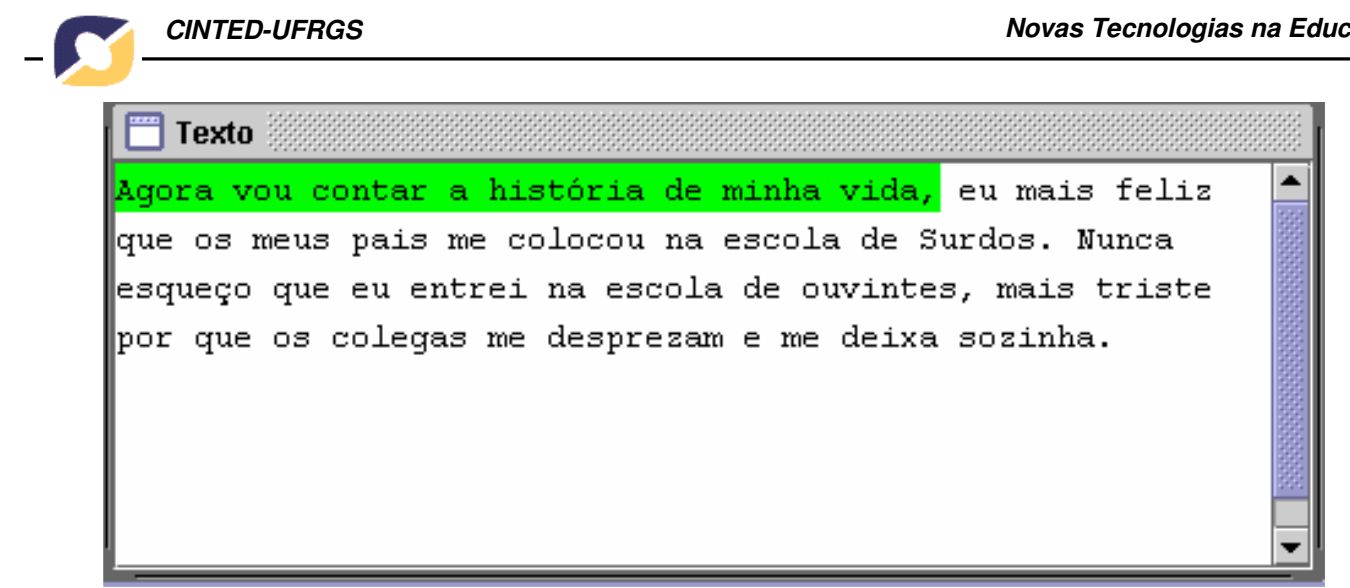

Figura 5: Texto ligado

O ambiente proporciona ao usuário ampla autonomia para determinar o posicionamento das janelas.

\section{CENÁRIO DE INTERAÇÃO}

Em um experimento piloto consideramos o cenário de interação em que uma usuária surda utiliza o software para relacionar uma narrativa em língua de sinais a um texto em português correspondente. Na execução deste cenário foi filmada uma narrativa pessoal com essa usuária em língua de sinais. Num segundo momento o próprio sujeito, assistindo a sua narrativa, escreveu o texto em língua portuguesa (segunda língua para o surdo). A participante foi uma surda adulta, fluente em Língua Brasileira de Sinais (Libras), com domínio da língua portuguesa escrita.

Inicialmente foi apresentado um exemplo ilustrativo de como realizar ligações entre vídeo e texto com o software. A participante não teve dificuldade de realizar por conta própria as ligações entre a sua história narrada em Libras e o seu texto escrito. Várias versões do texto escrito foram feitas a partir da constatação de que a primeira versão comunicava menos do que a narrativa original em Libras (o que fica muito visível quando o sujeito se propõe a fazer as ligações entre as duas línguas). No momento em que as ligações são realizadas as diferenças e os desencontros entre as duas formas de representação lingüística ficam evidentes. Também surgem de forma concreta as limitações que o sujeito possui no domínio da língua escrita. Quando isso se evidencia para o sujeito, produz-se uma desequilibração (Piaget, 1976), podendo gerar as tentativas subsequientes de aprimoramento.

$\mathrm{Na}$ Figura 6 pode-se visualizar a primeira versão do texto escrito pela usuária e a ligação entre o texto e o vídeo em que ela sinaliza em Libras. Fica também evidente na figura o layout da interface do ambiente computacional para o desenvolvimento de um projeto: 


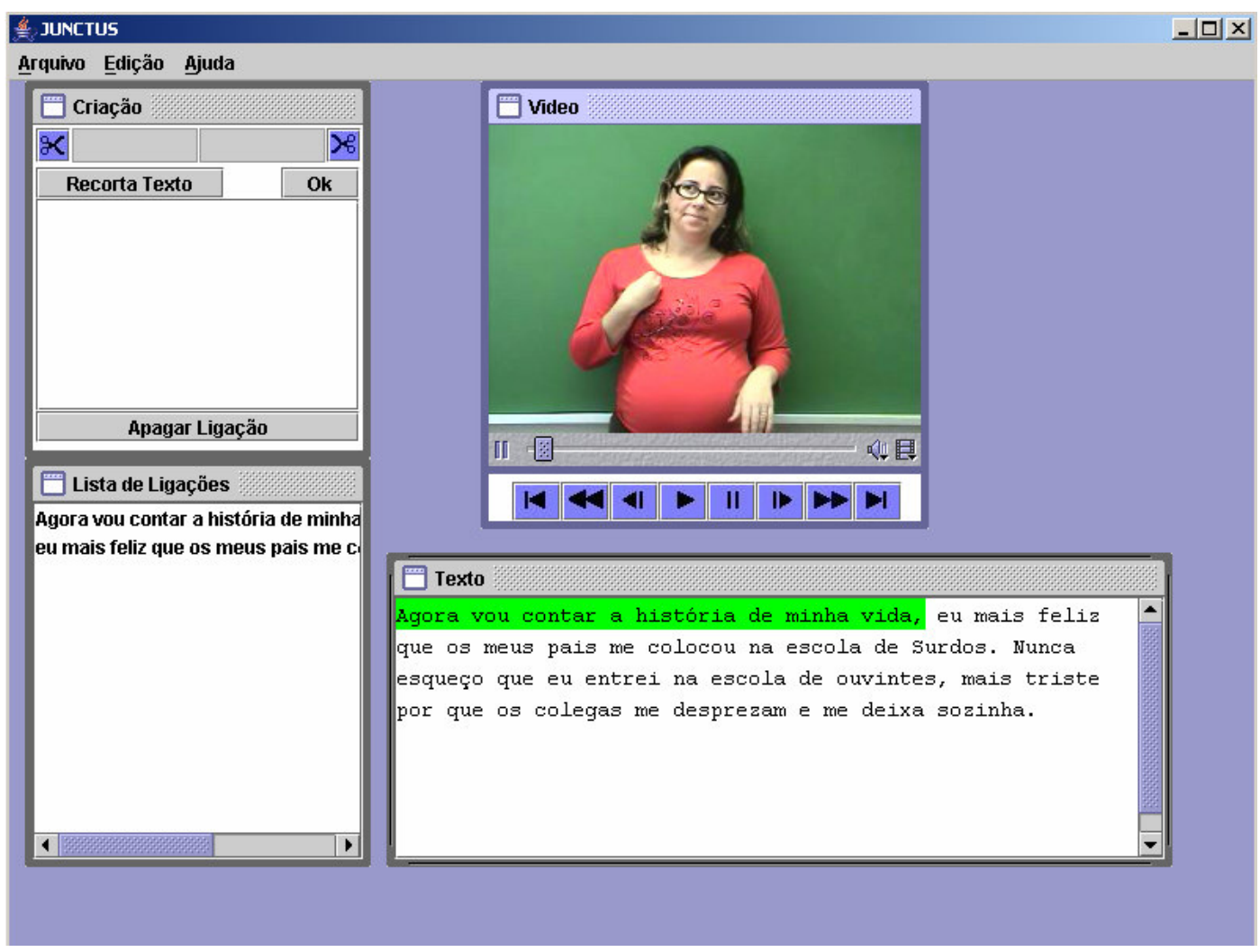

Figura 6: Projeto da Participante (Cenário de Interação)

Segundo Valentini (1995), a qualidade das interações em língua natural e em língua escrita podem levar à perturbações que são o motor da construção cognitiva, ou seja, o fator propulsor do desenvolvimento. Como conseqüência desse movimento cognitivo, o sujeito vê a língua escrita como objeto de conhecimento, empenhando-se em compreendê-la e dar-lhe significado. O ambiente informatizado pode favorecer atividades operatórias com relação à língua escrita, permitindo assim uma apropriação ativa desse objeto de conhecimento pelo sujeito, pois as interações, nesse contexto, não são só sociais, mas também simbólicas e cognitivas. Estudos têm demonstrado as vantagens da interação com computador para a apropriação da escrita e para $o$ desenvolvimento cognitivo do surdo.

O software pode permitir que o surdo se expresse em Língua de Sinais em primeiro lugar, sendo isso importante por ser sua língua materna. Em seguida, permite que a mesma narrativa seja construída em língua escrita, comparada e relacionada com a língua de sinais. Esse recurso permite considerar a relação entre esses dois códigos lingüísticos, possibilitando ao usuário estabelecer relações, compreender as diferenças e criar estratégias próprias de uso dessas duas línguas. 


\section{CONSIDERAÇÕES FINAIS}

O software de autoria Junctus mostrou-se funcional e de fácil apropriação por parte dos usuários. Vê-se pelo menos três aplicações importantes para este software livre: em projetos de pesquisa preocupados em compreender as relações que o usuário surdo de língua de sinais estabelece com a língua escrita e os processos de aprendizagem que daí podem ser favorecidos, no processo de ensino e aprendizagem para crianças e adolescentes surdos e em outros contextos educativos não necessariamente relacionados com PPNEEs. É importante ressaltar que a arquitetura interna do software foi definida de forma a facilitar futuras extensões com novas formas de representação. Portanto, o sistema pode ser utilizado também como plataforma para o estudo da interação em ambientes com múltiplas formas de representação.

O software foi apresentado a um grupo de professores de uma escola especial para surdos que trabalham com uma proposta bilíngüe de educação. Esta proposta de educação parte do pressuposto de que a língua de sinais é a primeira língua para o surdo e fundamental para o seu desenvolvimento cognitivo e emocional, a língua escrita é trabalhada como uma segunda língua: "Quanto ao ensino da língua portuguesa, a proposta bilìngüe para surdos concebe o seu desenvolvimento baseado em técnicas de ensino de segundas línguas" (Quadros, 1997, p. 29). O grupo de professores visualizou diferentes possibilidades de aplicação, como a construção de dicionários, construção de histórias infantis clássicas recontadas pelos surdos e criação de novas histórias.

Para além do uso com PPNEEs, o software pode ser adaptado a diferentes propostas pedagógicas, como por exemplo, o ensino de línguas estrangeiras. Também pode ser utilizado para crianças em processo de alfabetização, onde o desenho de uma história ou o contar oral dessa história pode ser transformado em texto escrito. Possivelmente os recursos lingüísticos utilizados pela criança, ao narrar oralmente sua história, não serão idênticos aos usados na língua escrita. A criança, ao realizar a transcrição de sua narrativa, poderá utilizar uma linguagem mais formal ao invés da coloquial. Além disso, o uso desse ambiente poderá auxiliar no processo de alfabetização e letramento, uma vez que poderão ser estabelecidas relações entre essas duas formas de representação. Nesse sentido, alfabetizar uma criança é conduzí-la ao domínio do processo de leitura e escrita; porém, orientá-la ao letramento é criar condições que ela possa praticá-las e exercitá-las.

O Junctus é um "ambiente de autoria" em que o usuário-aprendiz desenvolve seus próprios projetos em que pode haver a produção de um vídeo, o desenvolvimento de um texto (com várias versões aprimoradas sucessivamente), a definição de ligações entre as formas de representação e finalmente a apresentação do "produto final" para os pares/professor.

\section{REFERÊNCIAS BIBLIOGRÁFICAS}

Barbosa, R. M. Ambientes Virtuais de Aprendizagem. Porto Alegre: Artmed, 2005. Java Technology. Disponível em: <http://java.sun.com/. Acessado em set 2005a. Java Media Framework 2.0 API Guide. Disponível em: $<$ http://java.sun.com/products/java-media/jmf/>. Acessado em: abril 2005 b.

Link-it. Swedish Institute for Special Needs Education. Disponível em: < http://www.sit.se/net/Specialpedagogik/In+English/Educational+materials/Deaf+and+H ard+of+Hearing > Acessado em: maio 2005.

Quadros, R.M. Educação de surdos: a aquisição da linguagem. Porto Alegre: Artes Médicas, 1997. 
Marchesi, A. El desarrollo cognitivo y lingüístico de los niños sordos. Madrid: Alianza Psicología. $2^{a}$ reimpresión, 1993.

Piaget, J. A equilibração das estruturas cognitivas. Rio de Janeiro: Zahar, 1976. Piaget, J. A formação do símbolo na criança. Rio de Janeiro: Zahar, 1978.

Transana 2.0. Disponível em: <http://www.transana.org/> Acessado em: maio 2005. Valentini, C. B., A Apropriação da Leitura e Escrita e os Mecanismos Cognitivos de Sujeitos Surdos na Interação em Rede Telemática. Dissertação de mestrado. UFRGS, 1995. 